\section{NEW NAME, SAME BRUSH}

Oral-B CrossAction

toothbrushes are to be re-named Oral-B Pro-Expert CrossAction. The name change is part of a repackaging design to help consumers differentiate the brush from the plethora of manual toothbrushes on offer at most retail outlets.

Pro-Expert CrossAction incorporates multi-tufted,

flat trimmed, end-rounded

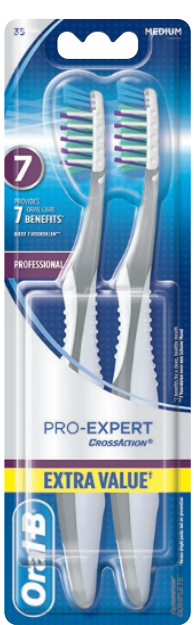

filaments which have been cleverly angled at $16^{\circ}$ in both directions to provide a brushing action that penetrates, lifts and sweeps plaque away on both forwards and backwards strokes. This enhanced capability removes plaque specifically from the areas normally least well served by brushing: the gingival margins, approximal surfaces and distal molars.

Pro-Expert CrossAction is a contemporary brush with design features that provide discernible patient benefits.

Reader response number 50

\section{PHARMACY AND DENTISTRY UNITE}

Waymade Healthcare Plc has been distributing and marketing products to UK pharmacies for over 27 years. In that time they've experienced phenomenal growth. The group now turns over in excess of $£ 250$ million and employs over 500 people. The next area in which to expand is dentistry.

Click Dental is the new dental division of Waymade Healthcare Plc. Click Dental will allow you to shop online for products with the same ease as doing your weekly online food shop. Once you've clicked on www.clickdental. com you won't be able to imagine buying dental products any other way. If you're still not certain, you can place an order by calling 08081080228 . Reader response number 51

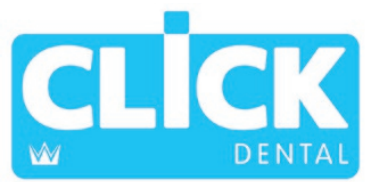

\section{BACKED BY SCIENCE}

'Power brushes with an oscillating-rotating action removed plaque and reduced gingivitis more effectively than manual toothbrushes in the short term and reduced gingivitis scores in studies over three months. No other powered designs were as consistently superior to manual toothbrushes.'

These words do not come from Oral-B, who developed the oscillating-rotating technology, but from The Cochrane Oral Health Group. Oscillating-rotating toothbrushes are also the only power products listed in

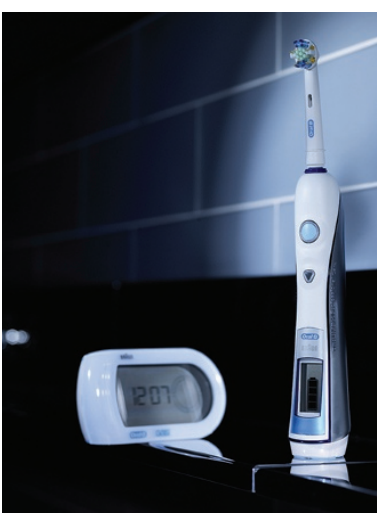
the Department of Health's 'Toolkit for Prevention'

Oral-B power toothbrushes are also the most used and recommended brand by dental professionals and are the only power brushes accredited by the British Dental Health Foundation.

Reader response number 52

\section{NEW DENTAL SEATING}

British healthcare equipment producer Meditelle has launched a new range of specialist dental seating under the Meditelle Dental brand. This unique dental product range is designed and manufactured in the UK for use by the whole dental team. It includes a large selection of chairs, stools and ergonomic seating including new and exciting posture saddle stool designs. A bespoke manufacturing service is also available and many products can be modified to meet the practitioners' own particular requirements, a facility that is particularly popular with dental customers. Meditelle dental equipment is specifically designed for the dental environment and comprises cost effective, quality equipment solutions.

Visit the website to see the new seating collection at www.meditelle-dental.co.uk. Reader response number 53

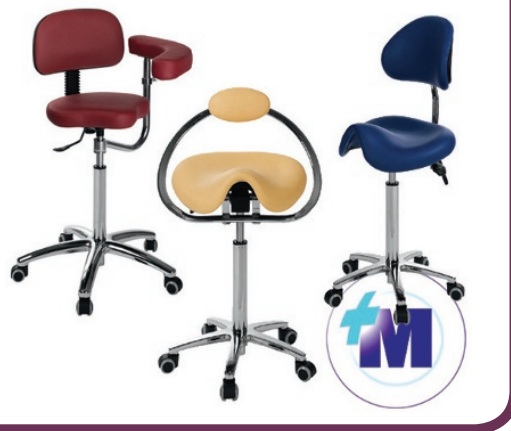

\section{WHITENING BUCKS THE RECESSION}

Despite recession, studies show a rise in patient demand for tooth whitening. Sonicare HealthyWhite is clinically proven to whiten teeth by up to two shades in two weeks. Its Clean \& White mode is designed to enhance the effectiveness of whitening treatments and remove extrinsic stains.

The Clean \& White setting increases brushing time by $25 \%$. After signalling the end of the two minute brushing session, HealthyWhite alters acoustically and sensorially to focus on the visible front teeth. Whilst patients are achieving the look they want, practitioners will appreciate the additional oral health benefits conferred by HealthyWhite.

Visit www.sonicare.co.uk/dp or call 08000567222.

Reader response number 54 